\title{
Socio-Economic Issues Storytelling for Closing Intergenerational Gap
}

\author{
Mohamed Buheji \\ Founder of the International Inspiration, Economy Project, Bahrain \\ E-mail: buhejim@gmail.com
}

Received: December 18, 2019 Accepted: January 8, 2020 Published: January 10, 2020

doi: $10.5296 /$ jsss.v7i1.16223

URL: https://doi.org/10.5296/jsss.v7i1.16223

\begin{abstract}
Stories have shaped people life since the beginning of humanity. Telling and sharing stories in an inspiring way is an art that has been deeply hidden with the heritage of many civilisations. In this paper, we investigate the influence of the new movement of storytelling on the intergeneration gap and their role in raising our curiosity about chronic socio-economic issues that are degrading the movement of humanity.

The paper focus on the best way of narrating poverty elimination stories and what improvements need to be done in projects that focus on reporting the results and the outcomes of the poverty labs, as the international project of inspiration economy.
\end{abstract}

Keywords: Storytelling, Intergeneration gap, Curiosity, Socio-economic issues, Poverty labs, Alleviation of generation gap, Social change

\section{Introduction}

Once the main characters of a story are that it can properly engage the audience with their environment. This engagement can help immerse people from different diverse backgrounds with the story and its problems, Buheji and Ahmed (2019). The people from a different background would have all the essential curiosity inputs of whether the story dilemma is solved or can be solved, or could be solved. The end of the story usually reflects the outcome or its theme. It gives the outcome of where we need the story to land (Buheji, 2019).

Intergenerational programs work in bringing community groups that match different generations interests together, especially elders with youth (Kuehne, 2013). Today, this is a challenge as the gap between the different generations is rising so far fast, and the extent of the gap is becoming larger and larger (Buheji, 2019b).

In this paper, the research investigates how the requirements for inspiring stories can influence its constructs. The uniqueness of storytelling is reviewed to see how it could help to enhance 
intergenerational learning, with more reference to the latest neuroscience studies. Finally, the relation of socio-Economic issues with storytelling is investigated to see how we could build a framework for storytelling that can spread awareness about socio-economic complexities and possible solutions (Price-Mitchel, 2016).

\section{Literature Review}

\subsection{Requirements for Inspiring Story}

Stories help us to see the world in new and different ways, and from a different perspective. The uniqueness of stories is that they shape our paradigm and move us toward action. Stories connect people's brains and make them work to create more new stories over time. This what makes people, communities work together to transform a current condition or maintain it, Coskie et al. (2010). Stories touch people heart, spirit, mind and influence how they react to the physical contents around them. Also, stories found to be inspiring because it makes people feel and share happiness, the challenges, the successes and the failures, thus sharing profound life experiences.

Price-Mitchel (2016) mentioned that a story might come as a result of an imagination effort, or about facts faced and overcome during a real-life journey. Hence, Polkinghorne (1988) believes that an inspiring story and storytelling might give a better meaning to life. An inspiring story pulls us to get engaged more with people's lives and thus develop over time our own views of the world (Thiam, 2016).

Whether we know it or not, stories make us take reflection and re-evaluate our life purposes and the values we live for. Choosing the story, we want to share create for us an excitement of curiosity, and thus makes us more curious to discover what is ambiguous. Our curiosity even goes higher if the story managed to engage more people for the cause of change, i.e. as changing a poverty status, or eliminating other risks of socio-economic issues (Buheji, 2019a).

\subsection{Constructs of Story and Storytelling}

Stories are made of a set of constructs that try together to make sense for a real or imagined event. These constructs are influenced by the way the story is physically presented to the targeted audience. Through sharing a story effectively, accumulated wisdom, beliefs, and values can be achieved. Through stories, we explain how things are, why they are, and our role and purpose. Today, we know more than stories are the building blocks of knowledge which improve the revival of our memory and lifelong learning. Stories connect us with past, present, and help us foresight the future. Through stories, we can anticipate the possible consequences of our actions (Jackson, 2005).

The other part that makes a story more compelling, especially when sharing it with other people is the act of narrating or telling the story. The act of telling a story emphasis that the teller is the medium that transforms the constructs of the story into images that can be realised by the audience. Therefore, the way the story is told would determine its level of communication outcome.

In order for storytelling to really create a differentiated outcome of the targeted audience, the main character, or the subject of the story need to be identified. The subject usually is a character or a creature, mostly humans. Through this creature, we feel the five senses as we 
are living within the story. The details of how this character deals with the surroundings in the story are what makes the story exciting and raise our curiosity (Buheji, 2019a).

Stories improve the logical and critical thinking, besides it improves empathy with others and, with others' cultures.

\subsection{The Uniqueness of Storytelling}

Storytelling is known to be today as interactive performance platform that establishes strong interaction between the teller and targeted audience. An audience responds to the teller words and actions, including the tones, the wording, and the pace of how the story is narrated to deliver its purpose.

The uniqueness of the storytelling is that it delivers the story after interpreting the experiences of the moments that create the story. The teller usually depends on the words of the story with limited visual images and make the targeted audience build their cognitive images based on the performer telling. Thus the storyteller should leave a space for the audience to experience the theme of the story and the use of multi-sensory images to create the reality of the story (Thiam, 2016).

\subsection{Storytelling for Intergenerational Learning}

Storytelling, as a process is an excellent medium for sharing and interpreting a specific content. Through storytelling, we can create experiential learning and dynamic interaction between the storyteller and the audience. The story creates a type of interaction that pull the participants to choose themes as facing the challenge. Storytelling integrates the performance of the past experiences and gives unique impressions that develop more visualisation and creativity in relevant to the content discussed. This visualisation raises the curiosity of the involved parties and strengthens their communication and social bond. Therefore, Buheji (2018) emphasised that storytelling help to transform the knowledge between all the parties involved. If storytelling is fixed as an exercise between the retired elders along with vibrant youth of today, it will create more possibility to enhance their companionship and dialogue. This would create much better intergenerational learning (Furlong, 2016).

The intergenerational learning of youth and the elders get them engaged to co-create new stories that help make sense of an ever-increasingly complex society. When youth and elders share stories, they bring meaning to life experiences and act as a conduit to learning, Furlong (2016). Elders learn what it is like for a young person to struggle with problems of today and to be more open to new possibilities. Studies now show that the storytelling exercise helps the elders to continue to learn and grow while keeping their own neuro networks alive and active (Cozolino, 2013).

\subsection{Neuroscience and Storytelling}

Cozolino (2013) emphasised that scientists have proven today that stories help humans to develop secure relationships, and thus help towards smooth brain development and learning. Neuroscience now shows that storytelling also stimulates productive inner learning as communication would flow effectively between the different generations. Storytelling creates a medium for different generations changes and the elder participants get energised. (Price-Mitchel, 2016). 
Studies of cognitive performance charts show that the general declines in cognitive processing speed and recall memory throughout adulthood can be controlled through storytelling. Once cognitive processing is controlled the speed of speech and coordination can be improved. Storytelling also found to help to improve the reaction times and dealing with challenging problems (Berger \& Quinney, 2010).

Storytelling found to crystallise intelligence, since they bring collective capacities of knowledge and accessibility to an expanding vocabulary and life experiences. Studies show that we all can have sustained crystallised intelligence even if we increase in age, if experience bank and metaphorical deposits are maintained (Berger \& Quinney, 2010).

Oatley (1992) sees that stories help to organise and integrate the neural networks of the brain as it carries contains emotions, thoughts, conflicts and resolutions. A story can stimulate the brain by the series of events and 'emotional components' that shap life, Jackson (2005). The mental templates for self-reflection help to transform life experiences of youth and stimulate their neuro networks. Storytelling gives us an opportunity of dedicated time where our story would be indeed heard and understood by other people while creating learning (Furlong, 2016).

\subsection{Intergeneration Storytelling for Socio-Economic Issues}

Creating and writing a socio-economic story helps to deliver 'core message', the structure of the socio-economic of challenge along it trigger the thinking about it. Research shows that besides improve the physical and cognitive capacity, involving youth with the elders in storytelling activities create a more positive influence on both the cost-effectiveness and overall mindset transformation (Oatley, 1992).

Having an intergenerational storytelling program of interest to all the different generations helps them stay socially engaged, Prasetyo (2017). Beyond that, the intergenerational storytelling found to carry out a piece of knowledge and cultural transmission value, where the unique mindset and wealth of experience of many elders are effectively transformed through compelling stories (Jackson, 2005).

Storytelling helps the different generations to share experience about mutual issues and community concerns. Hence, if storytelling engages people in socioeconomic issues and ensures they remember facts, or break down barriers of isolation. Therefore, the different generations of crystallised intelligence can be modelled through storytelling, which can provide younger generations with unique opportunities for cultural learning and exchange (Coskie et al., 2010).

The socio-economic sequence of events can be turned into an exciting story that can be shared between the different generations and extract from them empathetic based solutions. Through stories that reflect the reality of the community, we could involve different generations and create opportunities that could help exchange experiences and ideas (Jackson, 2005).

\subsection{Storytelling and Social Capital}

Having an intergenerational program that can harness the untapped potential of older adults and youth while addressing community challenges sure is an investment in the social capital. (Furlong, 2016).

Storytelling found to attract many generations to remain socially engaged and productive. 
Bring stories that have been solved from the utilisation of the social capital through for example utilising the neighbourhoods economy and entrepreneurship help to give exclusive access (Prasetyo, 2017).

Coskie et al. (2010) emphasised that every tale brings the community closer. Prasetyo (2017) sees that the critical elements of community development processes are how to share the learning.

\subsection{Storytelling as a Community Development Tool}

Bringing actual case studies into storytelling help the people to think and feel about their worlds and how they should interact with it or create differentiation in it.

As part of the community development processes, sharing stories or experiences can build trust, cultivates norms, transfers tacit knowledge, facilitates unlearning, and generates emotional connections.

Socio-economic issues stories teach us how to deal with the different community challenges and situations by finding solutions from these problems and working on alternative as opportunities. Storytelling helps the problem facilitator is to show the opportunities available for the socio-economic issue and what type of potential outcomes targeted or achieved.

Storytelling helps to enhance sharing the knowledge as it uses anecdotes to deliver the lessons learned which the pillar of community development. Through communicating experiences with socio-economic problems, we can build trust and empathy (Buheji \& Ahmed, 2019).

Numerous community development initiatives worldwide aspire to contribute to transformative change by using the transfer of knowledge. Therefore, narrating an actual story about a community challenge makes the rest of the community deal with new challenges and see better alternative futures.

Managing to turn many socio-economic change case studies into stories can help to sustain community development initiatives. Its context and basic constructs would influence the story. The socio-economic issue needs to be covered from its past and present then followed by its societal challenges.

Reporting a case study through storytelling help to frame reality and evoke imagination. For example, it would help to frame for the community what are the choices that need to be identified and which could potentially shape the outcome.

Each socio-economic story constitutes the opportunity for exploring how to engage people in meaningful and lasting change. Storytelling, as an approach, to help the problem solvers to connect with a culturally diverse audience and trigger their social capital towards specific social change. When storytelling builds trust, it unlocks the passion, the interest, and the curiosity of the community (Buheji, 2019a; Prasetyo, 2017).

\section{Methodology}

Based on the synthesis of the literature review, the following variables were identified in relevance to what could make the socio-economic issues suitable for storytelling and could help to trigger the interest of both youth and elders, as part of closing the intergenerational gap program, Buheji (2019b). 
There were three main repeated issues emphasised in the literature reviewed that could make a differentiation in engaging the different generations with the socio-economic stories, if narrated accurately. The precise character or the subject reporting, or taking part in the socio-economic story. The other primary input expected in any socio-economic story is the multi-sensory images mentioned, besides finally, the actions or the events that manage to attract the audience to the reality of the story.

Based on the review of the Inspiration Economy Socio-Economic Case studies mentioned in Buheji (2017) and Buheji (2018) which set the basis on the concept of inspiration economy and its way of solving community problems, twenty cases were evaluated for their fitness for being developed towards stories. Each case was assessed for its capacity to be developed towards having a character around whom the story could be narrated, whether it is embedded with multi-sensory images, and whether they can be described with full actions/events that can attract the concerned parties (Buheji \& Ahmed, 2019).

Finally, the paper goes to use the outcome of the comprehensive table towards suggesting suitable framework that would enhance the engagement of the different generation with the socio-economic stories, once they are narrated.

\section{Case Study}

This case is based on the projects and cases that came out of the International Inspiration Economy Project (IIEP) that started in Slovenia in September 2015 and spread later in countries as: Bahrain, Bosnia, Morocco, Sudan, Ghana, Kyrgyzstan. We have taken the main published cases made in the first three years of this project, i.e. until September 2018. These reference cases were selected due to their being a consistent reference in the main books of reference for the concept of inspiration economy, besides being a model that sustained and proven its influence on the community. Table (1) checks the potential of the 20 cases listed for being suitable for both being a story that can be narrated, then for bring suitable for intergeneration engagement program.

Table 1. Type of case reported/published with potential of becoming a narrated story

\begin{tabular}{|c|c|c|c|}
\hline $\begin{array}{l}\text { Name of Case Study Story } \\
\text { (with references) }\end{array}$ & $\begin{array}{l}\text { Does it have } \\
\text { Defined Subject } \\
\text { (Person or Character } \\
\text { around whom the } \\
\text { story could be } \\
\text { narrated)? }\end{array}$ & $\begin{array}{l}\text { Is the Case/Story } \\
\text { Reported Effective } \\
\text { in Using } \\
\text { Multi-Sensory } \\
\text { Images? }\end{array}$ & $\begin{array}{l}\text { Is the } \\
\text { Case/Story } \\
\text { Reported Full } \\
\text { of Actions/ } \\
\text { Event that } \\
\text { attract the } \\
\text { Concerned } \\
\text { Parties? }\end{array}$ \\
\hline $\begin{array}{l}\text { Case 1-Inspiring } \\
\text { (Buheji, 2017) }\end{array}$ & No & Can Be & Yes \\
\hline $\begin{array}{lr}\text { Case 2-Effective } & \text { Social } \\
\text { Development } & \text { Program } \\
\text { (Buheji, 2017) } & \end{array}$ & No & Can Be & Yes \\
\hline
\end{tabular}


Case 3-Early detection of Can Be

Can Be

Yes

non-communicable diseases

(NCDs)

(Buheji, 2017 and 2018)

Case

4-Enhancing No

No

Yes

Availability of Hospitals Beds

for Emergency Patients

(Buheji, 2017 and 2018)

Case 5-Elimination of Water Can Be Can Be $\quad$ Yes
Loss

(Buheji, 2017 and 2018)

Case 6-Elimination of Fast No

No

Yes

Food Poisoning (Buheji,

2017)

Case 7-Anxiety Management Can Be

Can Be

Yes

(Buheji, 2017 and 2018)

Case 8-Sanitary system No

No

Yes

blockages (Buheji, 2017 and

2018)

Case 9-Re-Inventing the Can Be

Can Be

Yes

Humanitarian Services

towards Eliminating Poverty

(Buheji, 2017 and 2018)

$\begin{array}{lr}\text { Case 10-Moving } & \text { Women } \\ \text { Empowerment } & \text { Program }\end{array}$

Can Be Can Be $\quad$ Yes

towards

Women

Advancement (Buheji, 2018)

Case 11-Eliminating Fatal No

No

Yes

Accidents (Buheji, 2017)

Case 12-Improving Main No

No

Yes

Electricity Supply

Connections (Buheji, 2017)

Case 13-Improving Can Be

Can Be

Yes

Production of Camel Wool

Carpets Industry \& Social

Capital (Buheji, 2017 and

2018)

Case

14-Re-Inventing No

No

Yes

Housing

Services 
Alternatives (Buheji, 2018)

Case 15-Fisheries Can Be

Can Be

Yes

Re-Development (Buheji,

2018)

Case 17-Elimination of $\mathrm{No}$

No

Yes

Jewellery Theft Incidence

(Buheji, 2018)

Case 18-Berber

Villages

Can Be

Can Be

Yes

towards

Eco-Tourism

(Buheji, 2018)

Case 19-Self Sufficiency No

No

Yes

Program in Middle Easter

Country (Buheji, 2018)
Case
20-
Youth Can Be
Can Be
Yes
Unemployment
(Buheji,
2018)

\section{Results}

As a result of the case study Table (1); Cases 3, 5, 7, 9, 10, 13, 15, 18 and 20 were identified to be suitable for being developed as stories that can be narrated and shared effectively. However, these cases need to be checked for being of interest to the different generations. Therefore, Table (2) targets to ensure the importance of the candidate story to both youth and elders as representatives of the different generations engagement with these socio-economic issues.

Table 2. Fitness of candidate stories for intergeneration engagement

\begin{tabular}{|c|c|c|}
\hline Candidate of Story & $\begin{array}{l}\text { Story Importance to } \\
\text { Youth }\end{array}$ & $\begin{array}{l}\text { Story Importance to } \\
\text { Elders }\end{array}$ \\
\hline $\begin{array}{l}\text { Case } \quad 3 \text {-Early } \quad \text { detection } \\
\text { non-communicable diseases (NCDs) }\end{array}$ & Yes & Yes \\
\hline Case 5- Elimination of Water Loss & $\begin{array}{l}\text { Maybe if connected to } \\
\text { Environment Issues }\end{array}$ & No \\
\hline Case 7-Anxiety Management & Yes & Yes \\
\hline $\begin{array}{l}\text { Case 9-Re-Inventing the Humanitarian } \\
\text { Services towards Eliminating Poverty }\end{array}$ & Yes & Yes \\
\hline $\begin{array}{l}\text { Case } 10 \text {-Moving Women Empowerment } \\
\text { Program towards Women Advancement }\end{array}$ & $\begin{array}{l}\text { Maybe from young } \\
\text { women }\end{array}$ & Yes \\
\hline Case 13-Improving Production of Camel & Yes & Yes \\
\hline
\end{tabular}




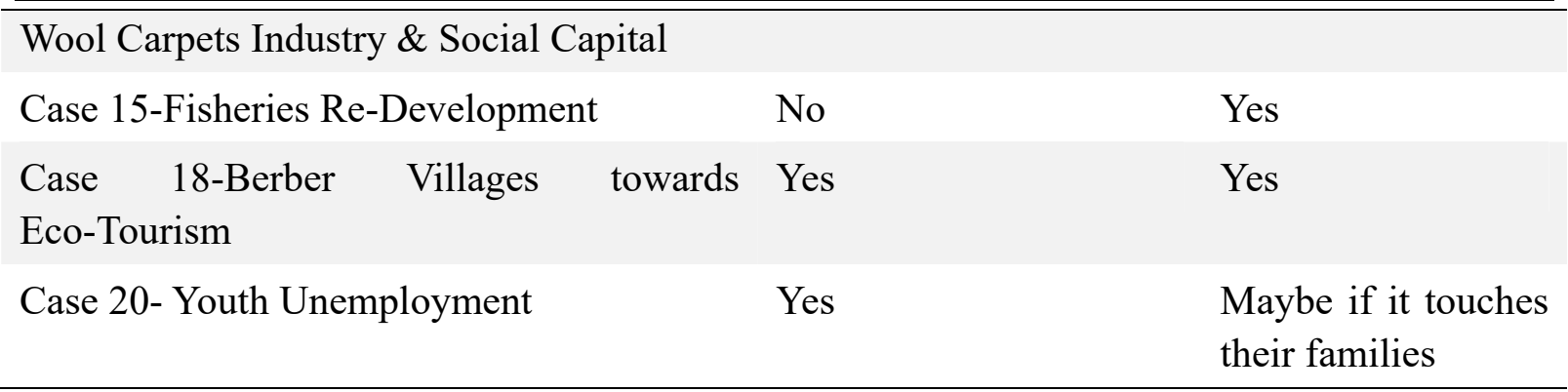

The outcome of the table shows that cases as early detection of communicable diseases, management of anxiety, re-inventing the humanitarian services, improve the livelihood of the camel wool industry social capital and stories on the Berber villages and how they are turning to be eco-tourism might bring the intergeneration gap closer. Besides, such stories have the potential of involving these different generations with such socio-economic issues.

\section{Discussion \& Conclusion}

\subsection{Framework for Selecting Socio-Economic Stories and Enhancing their Influence on} Intergeneration Engagement

The outcome of the case study and the results shows that having a carefully selective case that can be turned into stories that could be narrated would help to improve the possibility of better social interaction, specifically with socio-economic issues.

The following framework help to choose the right story and how it could be prepared for narrating or told in a way that it would engage the targeted audience. The framework is focused on building a dialogue between the different generations and raise their capacity and interests in recognising their community issues and challenges. The target of the framework is to raise the acceptance of the different generations for different challenges that face their socio-economic issue and thus to suggest solutions from different perspectives or to bring a comprehensive solution that influences the quality of the outcome.

The proposed framework, shown in Figure 1, starts with the selection of deep socio-economic community issue. Then, mechanisms of moving a socio-economic case to a story is filtered by three variables: the character of the story, the multi-sensory images in the story and the actions and the events that create more potential for intergeneration engagement. Once both youth and elders interest meets, then socio-economic engagement is guaranteed. However, if there are no interest from either or both generations then we need to go back to select the socio-economic community issue again. 


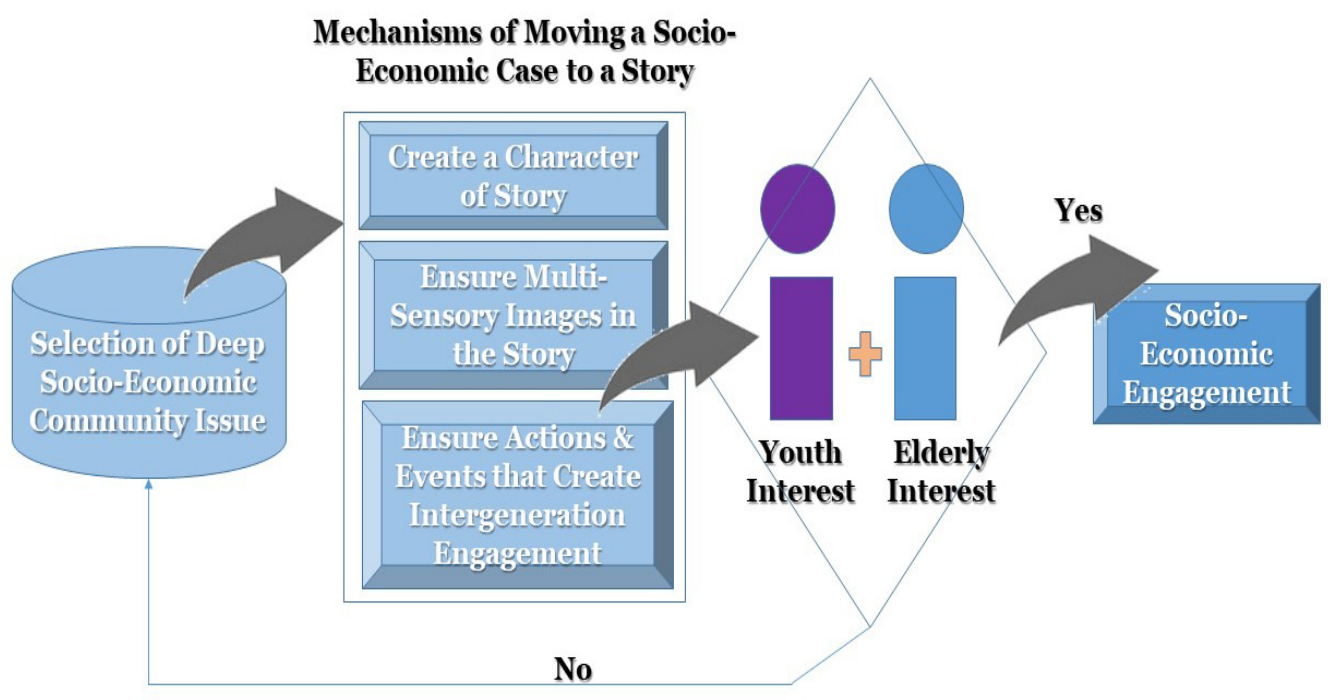

Figure 1. Framework for selecting socio-economic stories that would lead to intergeneration engagement

\subsection{Exposure of Socio-Economic Storytelling}

Despite this paper could not reach the stage where the storytelling would be tested for its influence on the different generations and in making them more involved with their community socio-economic issues, Figure 1 proposed framework has set the scene for how a story should be told.

Therefore, this paper recommends more further work on storytelling to ensure how it would raise the capacity of the different generations to exchange knowledge and experience the community issues and to inspire them to extract the best outcomes or solutions. This can be achieved by testing the experiential learning that is focused on facilitating better communication and inspire more engagement with communities issues and challenges.

\subsection{Limitations and Implication of this Paper}

The limitation of this paper is that the inputs of the case study were carried by the researcher and that none of the cases presented in the case study has been carried to the stage of being a complete story as the requirement discussed in the methodology. However, despite these shortages, the paper has lots of implications for those interested in creating social impact, or creating sustainable results on their communities. The other implication of the paper opens a new approach for problem solvers towards bringing in solutions that could change or strengthen their targeted outcome.

\subsection{Final Conclusion}

They are a common thread that brings in socio-economic issues, stories, storytelling and intergeneration gap, that is the need for unique evolving communication model in all of them. Having one communication model similar to the proposed framework along with the utilisation of the Tables 1 and 2 might create a significant transformation in how we deal with socio-economic issues in social labs, behavioural and inspirational economics projects and even how we report future foresighted socio-economic problems. More research in this area 
is highly needed to address the rising complications and influence of socio-economic issues on our communities progress and development.

\section{References}

Buheji, M., \& Ahmed, D. (2019). The Defiance - A Socio-Economic Problem Solving (Edited Book), AuthorHouse, UK.

Buheji, M. (2019a). Designing a Curious Life, AuthorHouse, UK

Buheji, M. (2019b). Alleviation of 'Generation Gap' Through Socio-Economic Issues Involvement. Review of European Studies, 11(4), 12-20. https://doi.org/10.5539/res.v11 n4p12

Buheji, M. (2018) Re-Inventing Our Lives, A Handbook for Socio-Economic "Problem-Solving", AuthorHouse, UK.

Buheji, M., \& Ahmed, D. (2017). Breaking the Shield- Introduction to Inspiration Engineering: Philosophy, Practices and Success Stories, Archway Publishing, FROM SIMON \& SCHUSTER, USA.

Berger, R., \& Quinney, R. (2010). Storytelling Sociology. Boulder, Colorado: Lynne Rienner Publishers.

Coskie, T., Trudel, H., \& Vohs, R. (2010). Creating Community through Storytelling. Talking Points, 22, 2-9.

Cozolino, L. (2013). The Social Neuroscience of Education: Optimizing Attachment and Learning in the Classroom: WW Norton \& Company.

Furlong, A. (2016). The changing landscape of youth and young adulthood. A. Furlong (Ed.), Handbook of Youth and Young Adulthood (pp. 3-11). Series: Routledge international handbooks. Routledge: Abingdon, Oxon; New York, NY. https://doi.org/10.4324/97813157 53058

Glass, T., Freedman, M., Carlson, M., Hill, J., Frick, K., Ialongo, K., ... Fried, L. (2004). Experience Corps: Design of an Intergenerational Program to Boost Social Capital and Promote the Health of an Aging Society. Journal of Urban Health: Bulletin of the New York Academy of Medicine, 81(1). https://doi.org/10.1093/jurban/jth096

Jackson, M. (2005) Storytelling Events, Violence, and the Appearance of the Past. Anthropological Quarterly, 78(2), 355-375. https://doi.org/10.1353/anq.2005.0020

Kuehne, V. (2013). Intergenerational programs: Understanding what we have created. Routledge. https://doi.org/10.4324/9780203725177

Oatley, K. (1992). Best laid plans: The psychology of Emotions. Cambridge: Cambridge University Press.

Price-Mitchel, M. (2016). Storytelling is Conduit for Intergenerational Learning, Psychology Today.

Thiam, S. (2016). The Value of Intergenerational Storytelling.

Prasetyo, Y. (2017). From Storytelling to Social Change: The Power of Story in the Community Building, SSRN Electronic Journal. https://doi.org/10.2139/ssrn.3094947 


\section{Copyright Disclaimer}

Copyright for this article is retained by the author(s), with first publication rights granted to the journal.

This is an open-access article distributed under the terms and conditions of the Creative Commons Attribution license (http://creativecommons.org/licenses/by/3.0/). 